\title{
Erratum to: Concepts and hypothesis: integrin cytoplasmic domain-associated protein-1 (ICAP-1) as a potential player in cerebral cavernous malformation
}

\author{
Yiming Zheng $\cdot$ Juhui Qiu $\cdot$ Jianjun Hu \\ Guixue Wang
}

Published online: 22 July 2012

(C) Springer-Verlag 2012

\section{Erratum to: J Neurol}

DOI 10.1007/s00415-012-6567-6

This original publication of the article contained errors owing to oversights in editing and typesetting. (1) In the second paragraph of the section "Direct evidence for the role of ICAP-1 in preventing excessive vascular growth", the word "inconclusive" was incorrectly changed to "conclusive". (2) The two reference citations in Figure 2 legend were wrong: the correct references are numbers 67 (not 68) and 42 (not 43). The publisher and authors sincerely apologize for these errors.

The online version of the original article can be found under doi:10.1007/s00415-012-6567-6.

Y. Zheng · J. Qiu · J. Hu · G. Wang (ه)

Key Laboratory of Biorheological Science and Technology

(Chongqing University), Ministry of Education,

Chongqing Engineering Laboratory in Vascular Implants,

Bioengineering College of Chongqing University,

Chongqing 400044, People's Republic of China

e-mail: guixue_wang@126.com; wanggx@cqu.edu.cn 